\title{
CHARACTERISTICS OF MOCVD-GROWN HIGH-QUALITY CDTE LAYERS ON GAAS SUBSTRATES
}

\author{
P. W. SZE AND K. F. YARN* \\ Department of Electronic Engineering, Nan-Tai Junior College of Technology, Tainan, Taiwan 710, \\ Republic of China
}

\author{
Y. H. WANG, M. P. HOUNG AND G. L. CHEN \\ Department of Electrical Engineering, National Cheng-Kung University, Tainan, Taiwan 701, Republic of \\ China
}

(Received January 10, 1995; in final form April 3, 1995)

CdTe epitaxial layers are grown successfully on a (100)-GaAs substrate by metalorganic chemical vapor deposition (MOCVD) using dimethylcadmium (DMCd) and diethyltelluride (DETe) as alkyl sources. The CdTe epilayers grown between $365^{\circ} \mathrm{C}$ and $380^{\circ} \mathrm{C}$ possess the best surface morphology. DETe is used as the controlling species of this growth system. Typical growth rates are varied from $2.5 \mu \mathrm{m} / \mathrm{hr}$ to $5.3 \mu \mathrm{m} / \mathrm{hr}$. Low-temperature (12K) photoluminscence (PL) measurements reveal that $380^{\circ} \mathrm{C}$ is the best growth temperature and the full width at half maximum (FWHM) of the dominated peak is about $1.583 \mathrm{eV}$ by the bound-exciton emission of $9.38 \mathrm{meV}$. The double crystal X-ray rocking curves (DCRC) indicate that the FWHM decreases while increasing the epilayer thickness and approaches a stable value about 80 arc sec under the growth rate of $5.2 \mu \mathrm{m} / \mathrm{hr}$, the growth temperature of $380^{\circ} \mathrm{C}$ and the $\mathrm{DETe} / \mathrm{DMCd}$ concentration ratio of 1.7. The value of 80 arc sec in FWHM is the smallest one ever reported to date.

\section{INTRODUCTION}

CdTe is a large bandgap, versatile II-VI compound semiconductor known for its wide use in infrared detectors ${ }^{1}, \gamma$-ray nuclear detectors ${ }^{2}$ and solar cells ${ }^{3}$. Because of its small lattice mismatch and the inherent high resistivity with $\mathrm{Hg}_{x} \mathrm{Cd}_{1-x} \mathrm{Te}, \mathrm{CdTe}$ is used as a substrate in preparing $\mathrm{Hg}_{x} \mathrm{Cd}_{1-x} \mathrm{Te}$ infrared detectors. However, the $\mathrm{CdTe}$ substrate material contains microscopic crystal defect such as subgrain boundaries and twins, which degrade the performance ${ }^{4}$ of infrared detectors made on the wafers containing such defects. Moreover, a large and high quality $\mathrm{Hg}_{x} \mathrm{Cd}_{1-x} \mathrm{Te}$ wafer is the suitable candidate for the next generation of twodimensional infrared detector arrays. Therefore, the selection of alternative substrates, such as $\mathrm{Si}^{5}, \mathrm{InSb}^{6}, \mathrm{GaAs}^{7}$ and sapphire ${ }^{8}$, is useful for growing $\mathrm{CdTe}$ thin film as a buffer layer to reach this purpose. Among these substrates mentioned above, GaAs is the most popular one due to its high resistivity and ease of

\footnotetext{
*All correspondence address to: K. F. YARN, P.O. Box 345, Tainan, Taiwan 704, Republic of China
} 
compatibility with high-speed III-V semiconductor devices. It also has been proved that high-quality CdTe epilayers could be grown on GaAs substrates, in spite of the large mismatch $(14.6 \%)$ between them.

To date, several methods including pulse laser evaporation (PLE) ${ }^{9}$, laser-assisted deposition and annealing (LADA) ${ }^{10}$, photo-assisted molecular beam epitaxy $(\mathrm{PAMBE})^{11}$, hot-wall epitaxy $(\mathrm{HWE})^{12}$, and metalorganic chemical vapor deposition (MOCVD) ${ }^{13}$ have been reported on the preparation of CdTe epitaxial layers. In the present work, under the consideration of easy control, lower growth temperature, and high quality of in-situ growth of $\mathrm{Hg}_{x} \mathrm{Cd}_{1-x} \mathrm{Te}$, a promising low temperature MOCVD method is adopted for growing CdTe buffer layer. Experimental measurements including surface morphology, film growth rate, X-ray diffraction, PL, and DCRC properties are investigated to analyze the film quality.

\section{EXPERIMENTAL}

The CdTe epilayers were grown at approximately atmospheric pressure in a rf-heated cold wall vertical reactor. Fig. 1 schematically shows an experimental apparatus. DETe and DMCd were used as source materials. They were separately kept at $20^{\circ} \mathrm{C}$ and $10^{\circ} \mathrm{C}$ in different temperature reservoirs for supplying the equilibrium vapor pressure of 7.1 torr and 16.8 torr, respectively. By using the mass flow controller, the amount of reactants put into reactor could be precisely adjusted. Palladium-diffused ultra-pure hydrogen was used as carrier gas and the total gas kept at 1.4SLM. The susceptor was rotated at $60 \mathrm{rpm}$ to get the uniform epilayers. The waste gases at the outlet of the growth chamber were passed through a resistance-heated furnace held at $800^{\circ} \mathrm{C}$, an activated carbon cell, and a burn-off unit to eliminate the harmful residual metal alkyls.

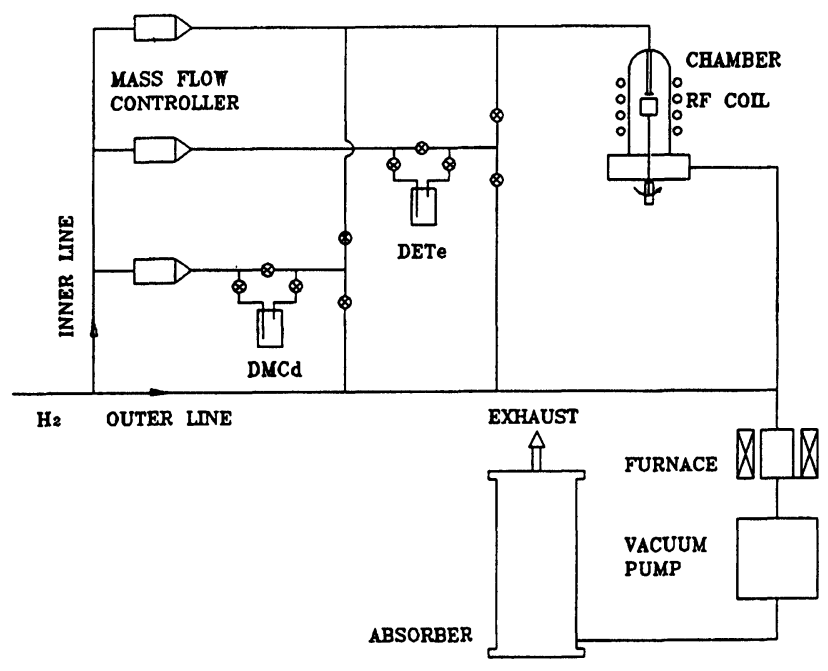

FIGURE 1 Schematical experimental apparatus. 
After degreasing, the GaAs substrate was etched by $\mathrm{H}_{2} \mathrm{SO}_{4}$ for 2-3 minutes and then loaded into the reactor at a growth temperature of $380^{\circ} \mathrm{C}$. In preliminary experiments, source gases with the same DETe/DMCd ratio of 1.0 were ejected from a quartz tube and then modulated by the different temperatures. After selecting the suitable growth temperature by a PL measurement, different DETe/ DMCd ratios were used to find the best growth condition.

The surface morphology and the thickness of CdTe epilayers grown on GaAs substrates were examined by using an optical microscope. To evaluate the CdTe film crystalline condition, we measured the X-ray diffraction of $(400)$ reflection with a spot size of $2 \mathrm{~mm} \times 2 \mathrm{~mm}$. Low temperature (12K) PL measurements were carried

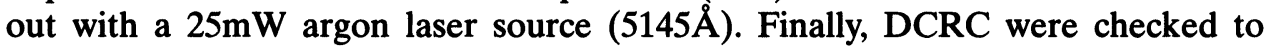
investigate the CdTe film quality.

\section{RESULTS AND DISCUSSION}

\section{Surface morphology}

The photomicrographs of CdTe epilayers grown on (100)-GaAs at $335^{\circ} \mathrm{C}, 350^{\circ} \mathrm{C}$, $365^{\circ} \mathrm{C}, 380^{\circ} \mathrm{C}$, and $395^{\circ} \mathrm{C}$ with equal amount of DETe and DMCd are shown respectively in Fig. 2. It has been reported that the existence of an oxide layer on the GaAs surface would lead to 3D growth for (100)-CdTe epilayers and form pyramids ${ }^{14}$. In Fig. 2, we find that the surface morphology of CdTe epilayers are strongly dependent on the growth temperature. The volume of pyramids are larger as the growth temperature increases and the best morphology is observed at $380^{\circ} \mathrm{C}$. At $380^{\circ} \mathrm{C}$, the pyramids are nearly the same and arrange in order. Below $365^{\circ} \mathrm{C}$, the epilayer shows a smooth surface with only a few pyramids due to the lack of surface kinetics for the deposited molecules. For growth temperature above $395^{\circ} \mathrm{C}$, a rugged and different volume of pyramidal surface is obtained owing to the escaping of $\mathrm{Cd}$ or $\mathrm{Te}$ atoms from the deposited surface at higher temperature.

\section{Growth rate}

In an MOCVD growth processes, the epilayer growth rate plays an important role on understanding the growth mechanism and predicting film quality. Fig. 3 shows the relationship between growth rates and $9.8 \times 10^{-4}$ mole $\%$ DETe/DMCd concentrations. The growth rates almost increase linearly with temperature between $335^{\circ} \mathrm{C}$ and $380^{\circ} \mathrm{C}$ and approach a maximum growth rate of $4 \mu \mathrm{m} / \mathrm{hr}$. In this temperature range, the growth rates are controlled by the reaction kinetics and the reaction activation energy is above $21.3 \mathrm{Kcal} / \mathrm{mole}$ by calculating the Arrhenius equation. About $380^{\circ} \mathrm{C}$, the growth rates fall off gradually. The decrease of growth rate at higher temperature in this work is attributed to the increased tendency of gas phase dissociation of metal alkyls ${ }^{15}$.

To examine whether the growth of a CdTe epilayer is reached to the mass transport limit or not, the test would be done by keeping the DETe/DMCd concentration ratio at a constant value of 1.0 and the growth temperature at $380^{\circ} \mathrm{C}$. The result is shown in Fig. 4. Initially, the growth rate increases linearly with the 
total concentration of metal alkyls. Above $2.86 \times 10^{-3}$ mole $\%$ concentration, the growth rate decreases gradually. This indicates that the total concentration of metal alkyls reaches that of transport-limited condition. Because the films tend to degrade at a total concentration of $3.42 \times 10^{-3} \mathrm{~mole} \%$, we therefore selected the value of 2.86 $\times 10^{-3} \mathrm{~mole} \%$ as the total concentration of metal alkyls in this experiment.

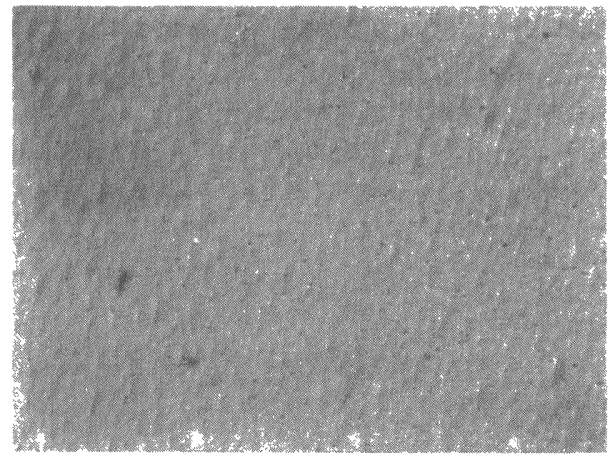

(a) $335^{\circ} \mathrm{C}$

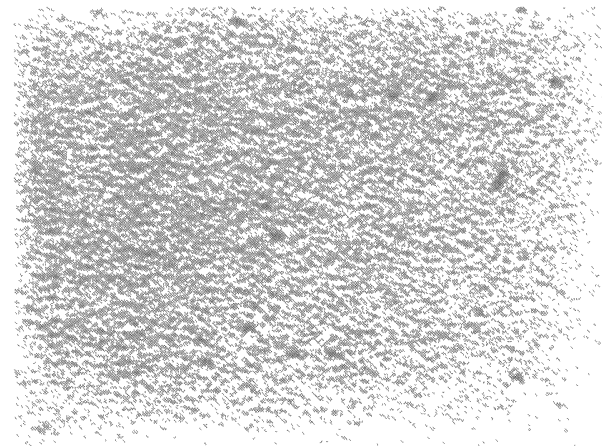

(b) $350^{\circ} \mathrm{C}$

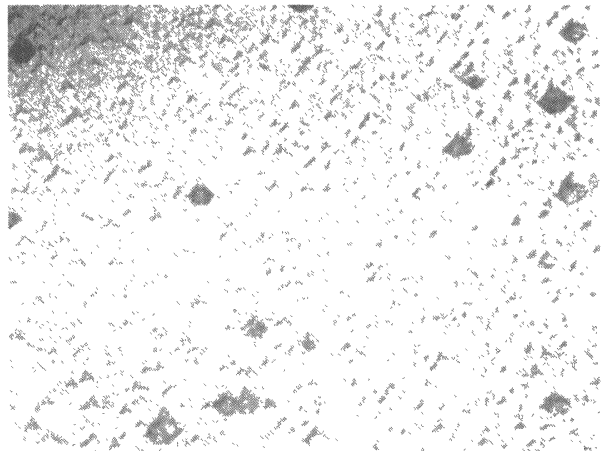

(d) $380^{\circ} \mathrm{C}$

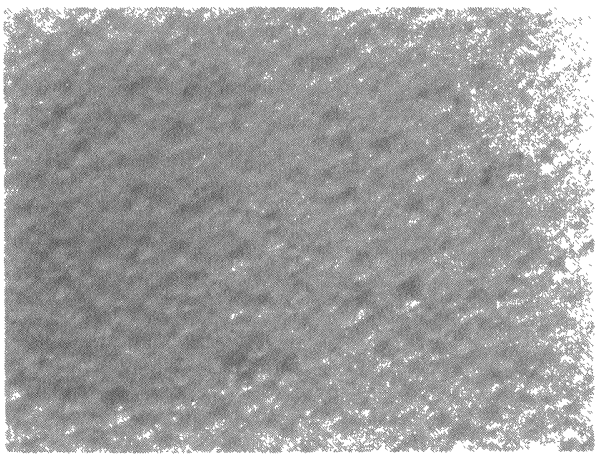

(e) $395^{\circ} \mathrm{C}$

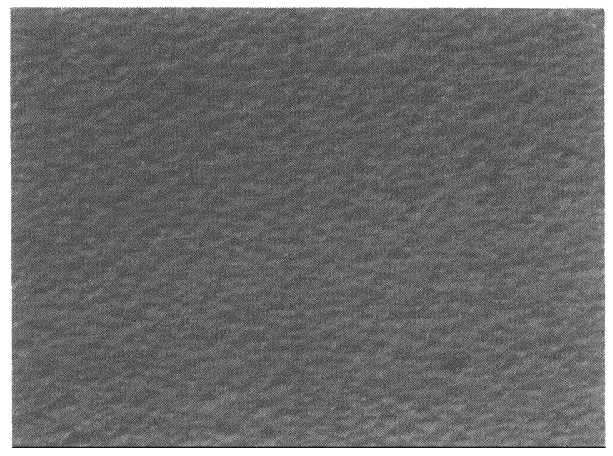

(c) $365^{\circ} \mathrm{C}$

FIGURE 2 Morphology of CdTe film on (100) GaAs substrate; (a) $335^{\circ} \mathrm{C}$, (b) $350^{\circ} \mathrm{C}$, (c) $365^{\circ} \mathrm{C}$, (d) $380^{\circ} \mathrm{C}$, (e) $395^{\circ} \mathrm{C}$, where the concentration of DCMd is $9.8^{*} 10^{-4}$ mole $\%$ and the DETe/DMCd ratio is equal to 1.0 . 


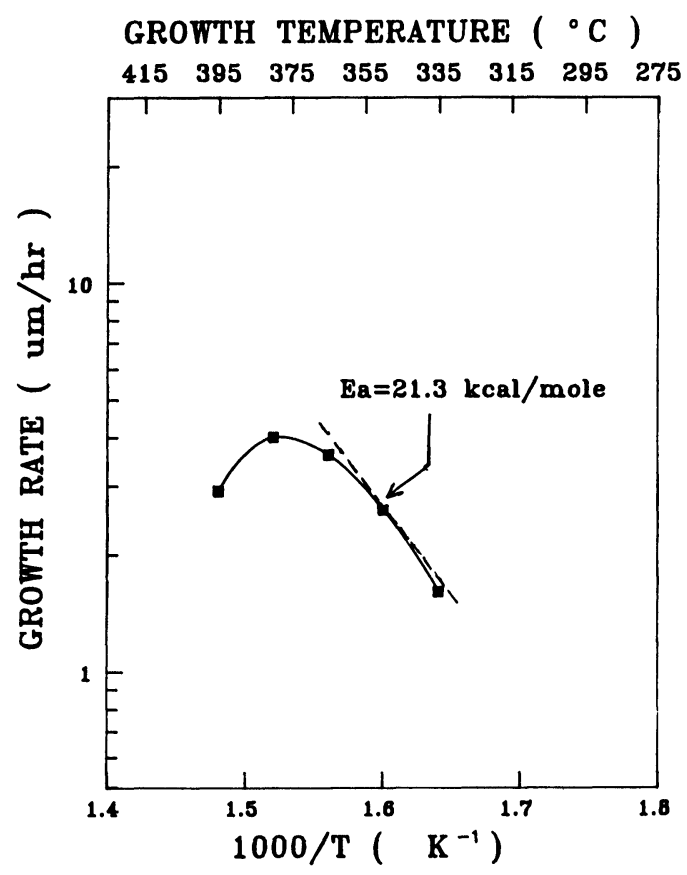

FIGURE 3 Variation of the growth rate as a function of growth temperature, where the concentration of DMCd is $9.8 * 10^{-4}$ mole \% and the DETe/DMCd ratio is equal to 1.0 .

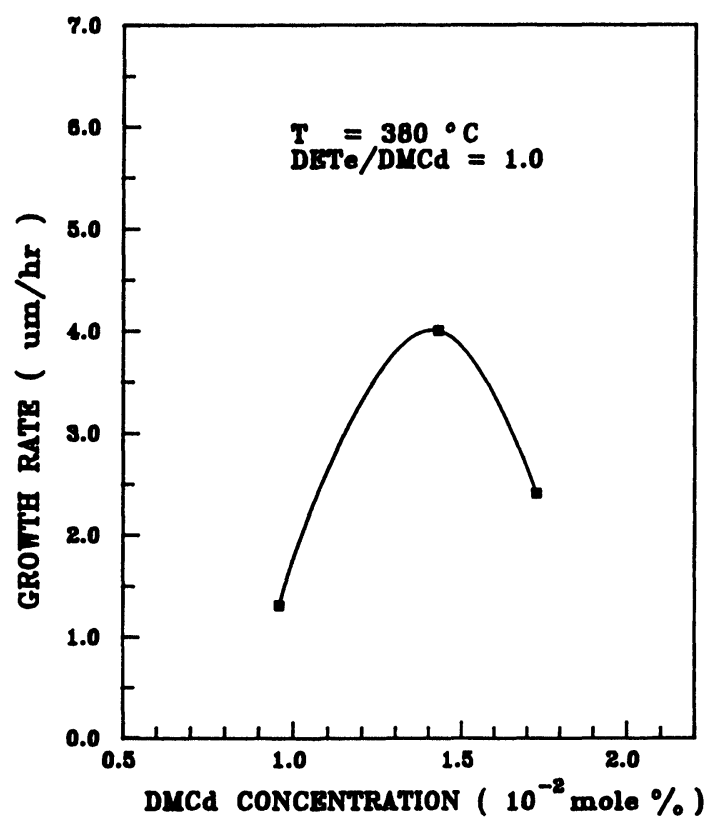

FIGURE 4 Variation of the growth rate at $380^{\circ} \mathrm{C}$ as a function of the total alkyl concentrations, where the concentration of DMCd is $9.8^{*} 10^{-4}$ mole \% and the DETe/DMCd ratio is equal to 1.0 . 


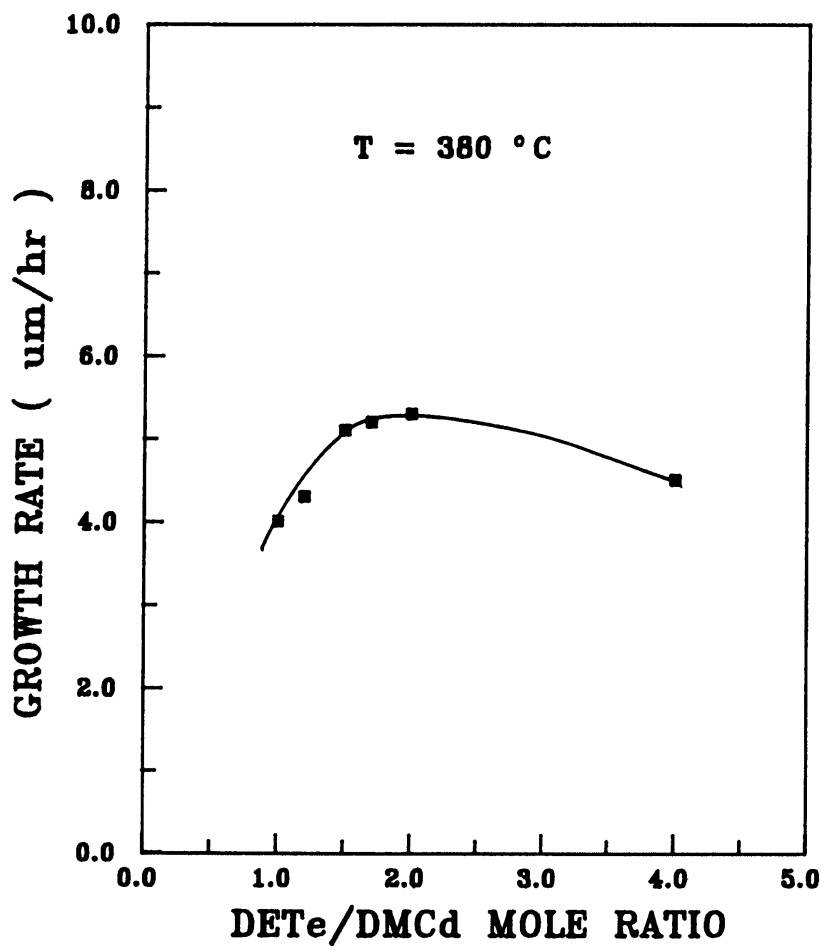

FIGURE 5 Variation of the growth rate at $380^{\circ} \mathrm{C}$ as a function of the DETe/DMCd ratio, where the concentration of DMCd is $9.8 * 10^{-4}$ mole\% and the DETe/DMCd ratio is equal to 1.0.

To find out the effect of DETe/DMCd ratio versus growth rate, a series of experiments were carried out at $380^{\circ} \mathrm{C}$. Here, we modulated the DETe concentration by fixing DMCd concentration and the result is shown in Fig. 5. Basically, the maximum growth rate occurs at the ratio of $1.5 \sim 2.0$. Below the ratio of 1.5 , the growth rate decreases. It is evident that DETe is the rate-controlling species during CdTe epitaxial growth. Above the ratio of 2.0, the growth rate also decreases. The reason is that the decomposition efficiency of the excess DETe alone is small at $380^{\circ} \mathrm{C}$ when the gas phase molecules are dominated by $\mathrm{DETe}^{16}$. Besides, there are the least defects on the top of pyramids in the range of $1.5 \sim 2.0$.

\section{$X$-ray diffraction $(X R D)$ analysis}

To examine the orientation and crystallization of CdTe epilayers, XRD analysis is used and diffraction patterns are shown in Fig. 6. Three diffraction peaks observed at $2 \theta=27.65^{\circ}, 56.95^{\circ}$ and $66.1^{\circ}$ under three temperature $\left(350^{\circ} \mathrm{C}, 365^{\circ} \mathrm{C}\right.$, and $\left.380^{\circ} \mathrm{C}\right)$ belong to (111)-GaAs, (400)-CdTe, and (400)-GaAs, respectively. It means that the CdTe epilayers are single crystal in (100) orientation. For the three deposition temperatures examined, no correlation between film orientation and growth temperature is evident. Similarly, there is no apparent relation between growth rate and film orientation when the growth rate varies from $2.6 \mu \mathrm{m} / \mathrm{hr}$ to $4.0 \mu \mathrm{m} / \mathrm{hr}$. 


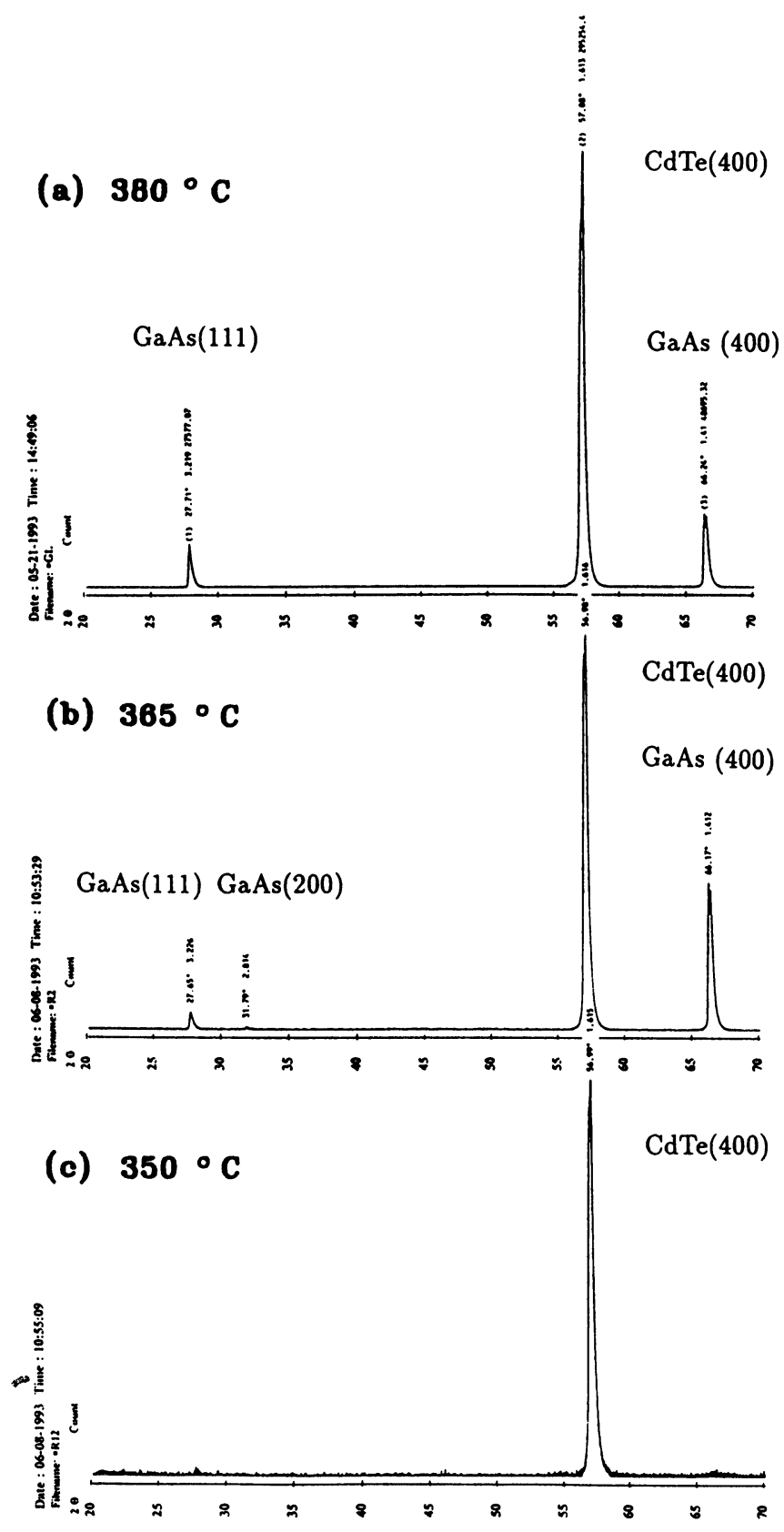

FIGURE 6 XRD patterns of CdTe epitaxial layers on GaAs substrate at (a) $350^{\circ} \mathrm{C}$, (b) $365^{\circ} \mathrm{C}$, (c) $380^{\circ} \mathrm{C}$, where the concentration of DMCd is $9.8 * 10^{-4} \mathrm{~mole} \%$ and the DETe/DMCd ratio is equal to 1.0. 


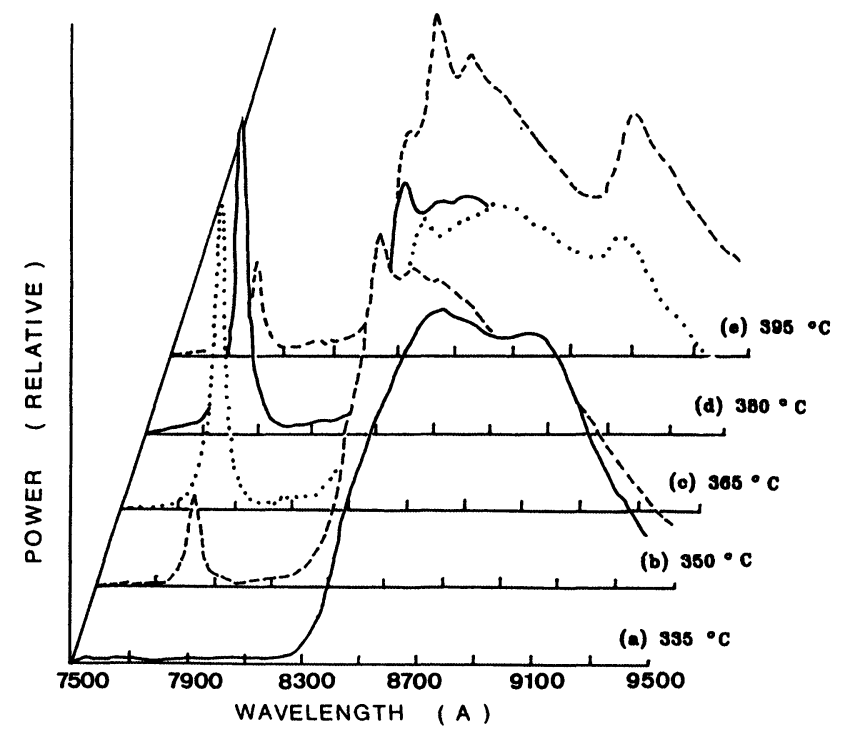

FIGURE 7 Low-temperature (12k) photoluminescence spectra of CdTe epilayers grown on GaAs substrate at (a) $335^{\circ} \mathrm{C}$, (b) $350^{\circ} \mathrm{C}$, (c) $365^{\circ} \mathrm{C}$, (d) $380^{\circ} \mathrm{C}$, (e) $395^{\circ} \mathrm{C}$, where the concentration of DMCd is $9.8 * 10^{-4}$ mole $\%$ and the DETe/DMCd ratio is equal to 1.0 .

\section{Optical properties}

The optical properties of CdTe epilayers grown at different temperatures with equal amount of DETe and DMCd are characterized by a $5145 \AA$ argon laser with output power of $25 \mathrm{~mW}$ under 12K. Fig. 7 shows the PL spectra of CdTe layers grown on $\mathrm{GaAs}$ substrates at different temperatures. A relative sharp peak at about $7820 \AA$ due to the bound exciton emission ${ }^{17}$ and a broad peak at long wavelength of $8500 \AA$ due to the so-called defect luminescence ${ }^{18}$ are observed. They also can be seen from the ratio of exciton intensity $\left(\mathrm{I}_{\text {exc }}=1.583 \mathrm{eV}\right)$ to the defect intensity $\left(\mathrm{I}_{\text {def }}\right.$ $=1.463 \mathrm{eV}$ ) shown in Fig. 8 which indicates that the best growth temperature appears at $380^{\circ} \mathrm{C}$. Simultaneously, Fig. 9 shows the FWHM of dominated peak at different temperatures and the minimum value of $9.38 \mathrm{eV}$ is obtained at $380^{\circ} \mathrm{C}$.

\section{DCRC analysis}

In this section, a DCRC analysis is used with a scan speed of $0.2 \mathrm{~mm} / \mathrm{sec}$ to identify the CdTe crystal quality. Fig. 10 shows the FWHM of the (400)-CdTe bragg reflex from (100)-CdTe/(100)-GaAs as a function of the CdTe thickness. A decrease of FWHM with increasing layer thickness is observed. Since the width of the X-ray rocking curve is sensitive to the extended crystal defects (e.g., dislocation lines) in the epilayer, thus, the data in Fig. 10 indicate a decreased density of extended defects with increasing epilayer thickness. Transmission electron microscopy (TEM) investigation of (100)- $\mathrm{CdTe} /(100)-\mathrm{GaAs}$ has shown a region $(\sim 0.1 \mu \mathrm{m})$ of very high dislocation density close to the $\mathrm{CdTe} / \mathrm{GaAs}$ interface forming a regular dislocation network and a decreasing dislocation density with increasing distance 


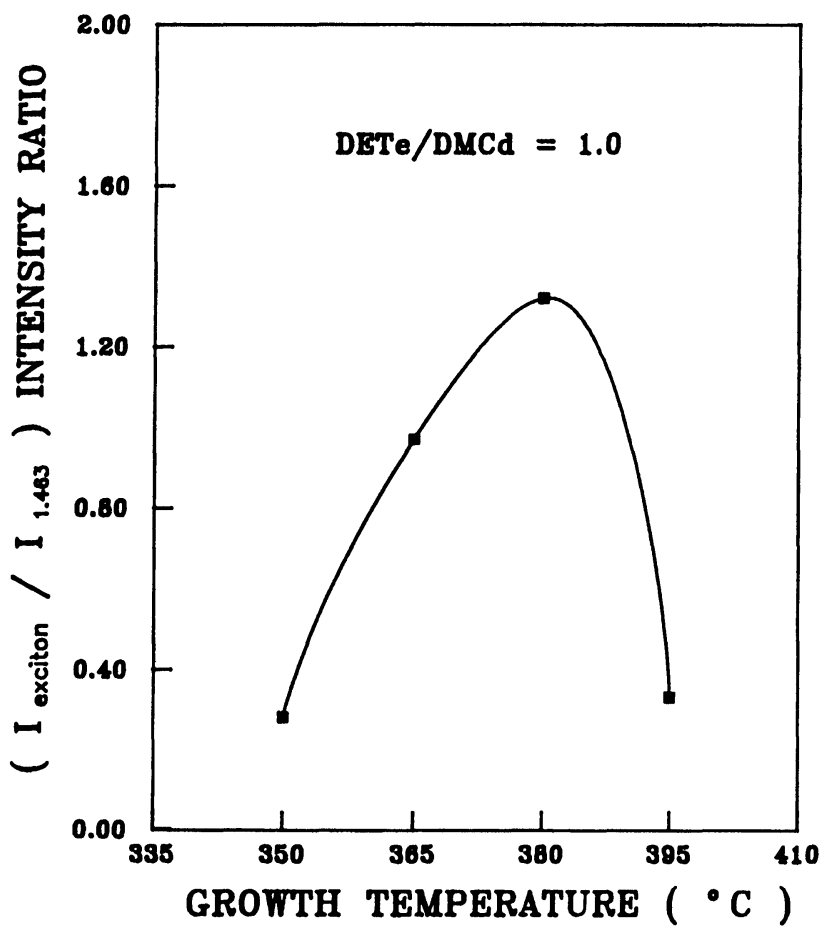

FIGURE 8 Intensity ratio of the bound-exciton emission line at $1.583 \mathrm{ev}$ to the deep-level emission at $1.463 \mathrm{ev}$ in CdTe prepared at different temperature, where the concentration of DMCd is $9.8^{*} 10^{-4}$ mole \% and the DETe/DMCd ratio is equal to 1.0 .

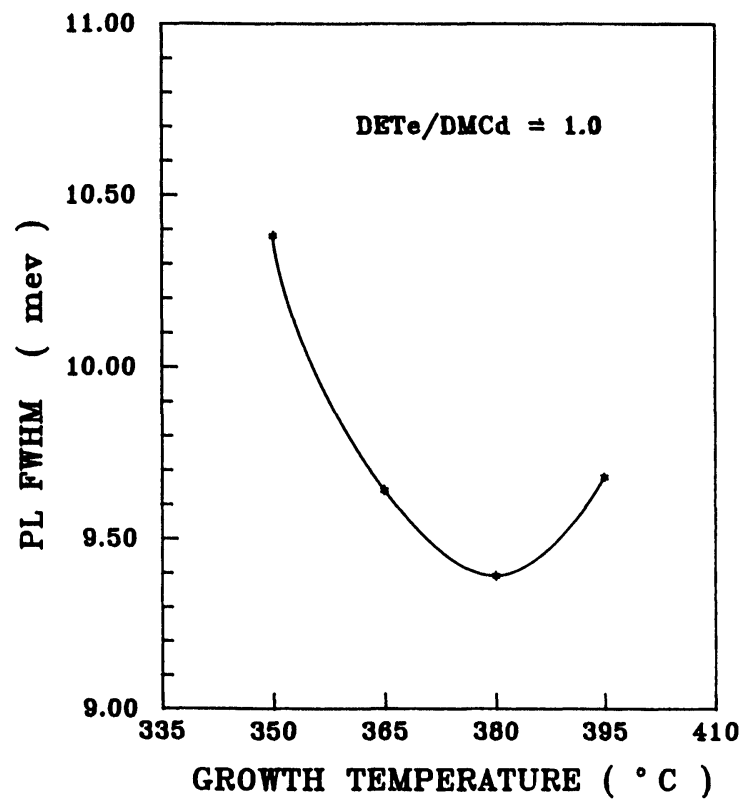

FIGURE 9 The FWHM of the bound-exciton emission line at $1.583 \mathrm{ev}$ in CdTe samples prepared at different temperatures, where the concentration of DMCd is $9.8^{*} 10^{-4}$ mole $\%$ and the DETe/DMCd ratio is equal to 1.0 . 


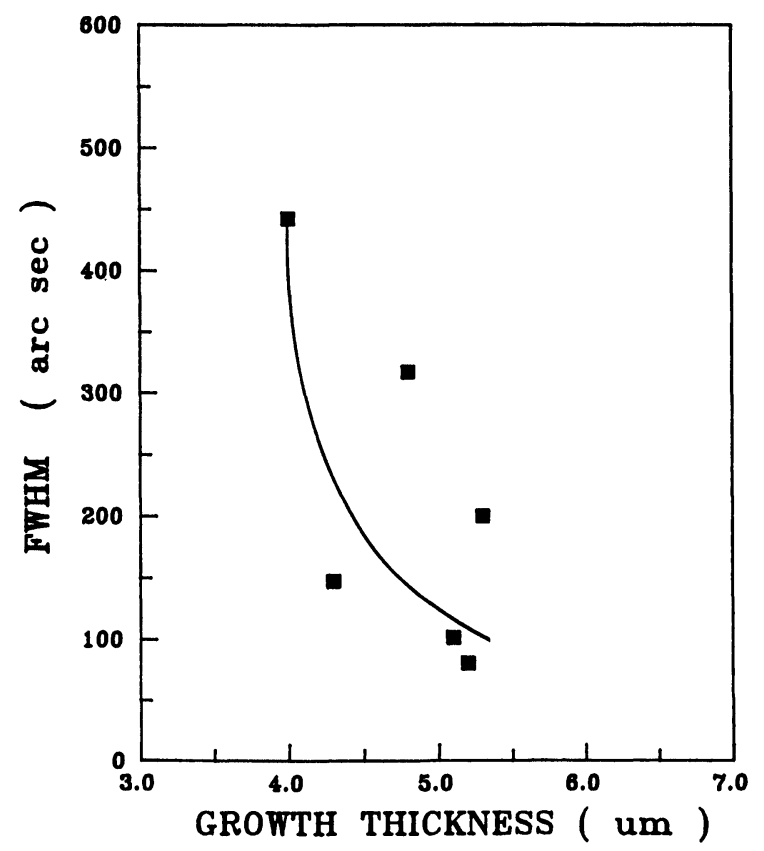

FIGURE 10 The width of (400) rocking curves, CdTe FWHM, versus the CdTe epilayer thickness, d, obtained from (100) oriented CdTe on (100) GaAs.

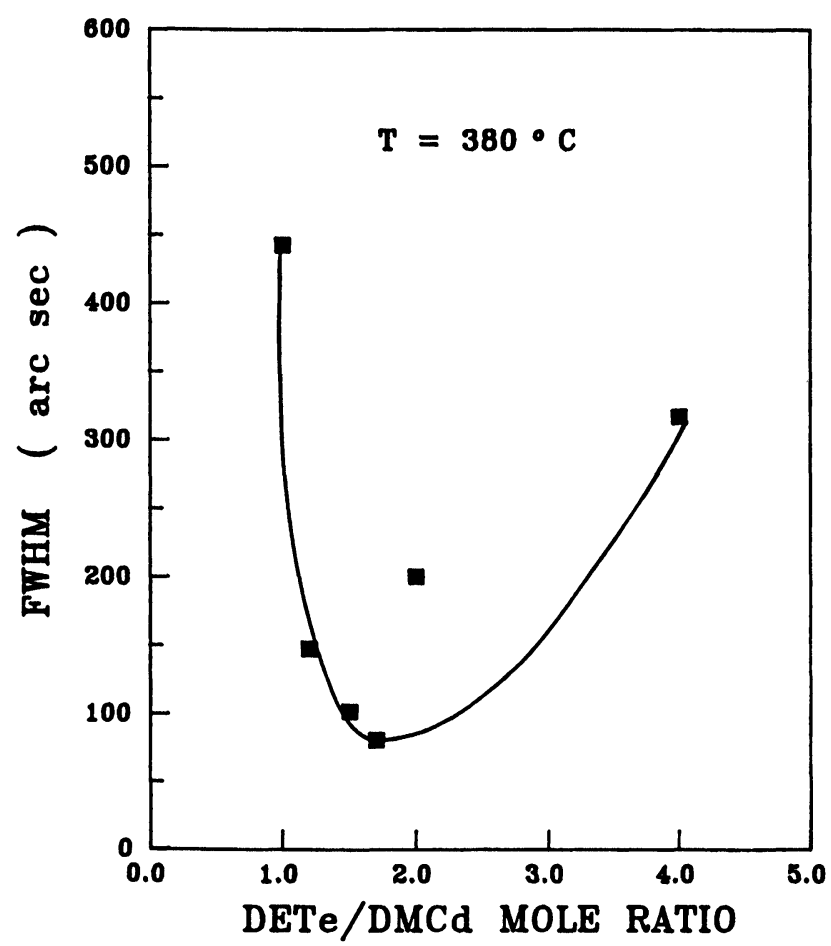

FIGURE 11 Variation of the FWHM of rocking curves at $380^{\circ} \mathrm{C}$ as a function of the DETe/DMCd ratio, where the concentration of DMCd is $9.8^{*} 10^{-4}$ mole \%. 


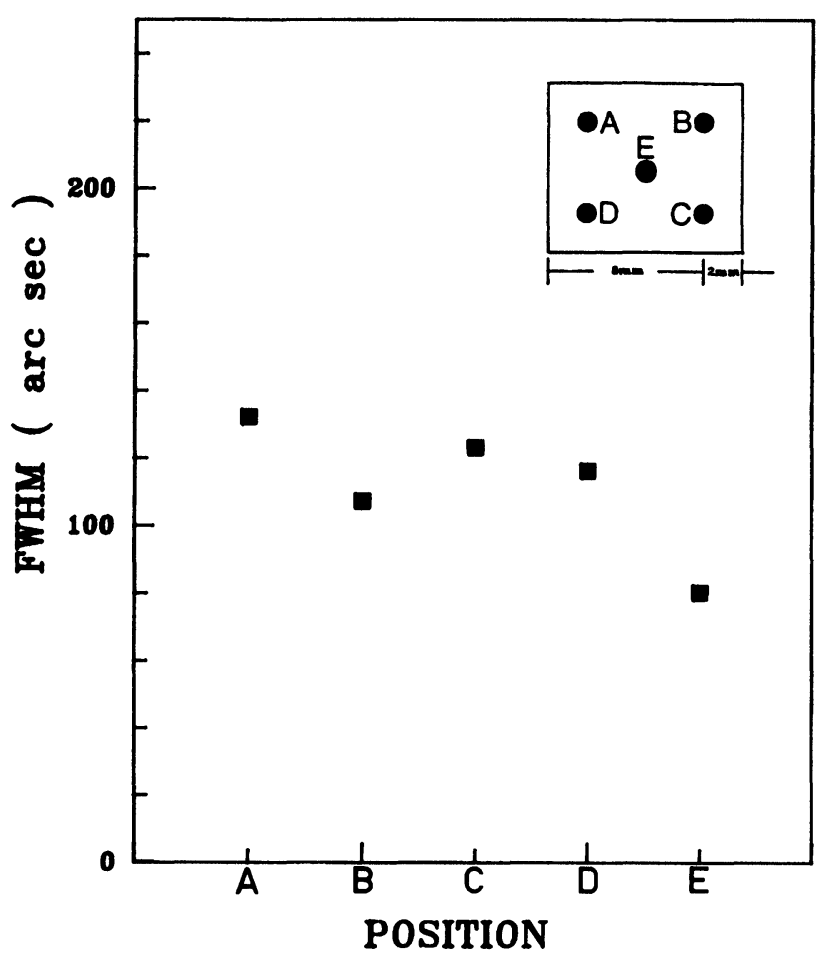

FIGURE 12 The experiment for examining the quality uniformity of CdTe epilayer grown at $380^{\circ} \mathrm{C}$ and DETe/DMCd ratio of 1.7 .

from the interface. Fig. 11 shows the relation of FWHM with different DETe/ $\mathrm{DMCd}$ concentration ratios in $380^{\circ} \mathrm{C}$. It is found that the minimum value is up to 80 arc sec when the concentration ratio is 1.7 .

For different positions in $10 \mathrm{~mm} \times 10 \mathrm{~mm}$ CdTe epilayers, a rocking curve analysis is tested and the result is shown in Fig. 12. We find that the FWHMs of the rocking curves are changed from 80 to 130 arc sec when the tested positions are moved from the center to the outside GaAs substrate. It may have resulted from the nonuniform distribution MO gas through the surface of the GaAs substrate. By adding the flow of hydrogen, it will make the MO distribution much more flatter.

\section{CONCLUSIONS}

High quality (100)-CdTe epilayers have been successfully grown on (100)-GaAs by the MOCVD method with DETe and DMCd as source materials. The activation growth energy in the reaction-limited growth region is $21.3 \mathrm{Kcal} / \mathrm{mole}$ and the DETe is the key element in controlling growth rate. Basically, the growth temperature controls the volume of pyramids by supplying enough surface kinetics. The modulation of DETe/DMCd concentration ratio also can decrease the density of defects. From the low temperature PL measurement, it is found that $380^{\circ} \mathrm{C}$ is the most suitable temperature for CdTe growth. Besides, the DCRC experimental 
results also show that the FWHM of CdTe films even at higher growth rate (above $5.1 \mu \mathrm{m} / \mathrm{hr}$ ) is low to $80 \mathrm{arc} \mathrm{sec}$, which is the best value ever reported.

\section{REFERENCES}

1. P. Vohl and C.M. Wolfe, J. Electron. Mater., 7, 659 (1978)

2. M.E. Jone, "Growth from Vapor", Treatise on Solid State Chemistry, 5, 283 (1975)

3. T. Shoji, K. Ohba and Y. Hiratate, Phys. Status Solidi, A57, 154 (1980)

4. H. Takigawa, T. Akamatsu, T. Kanno and R. Tsunoda, IEDM Technical Digest, p172 (1981)

5. Y. Lo, R.N. Bicknell, T.H. Myers, J.F. Schetzina and H.H. Stadelmaier, J. Appl. Phys., 54, 4238 (1983)

6. H.A. Mar, N. Salansky and K.T. Chee, Appl. Phys. Lett., 44, 898 (1984)

7. H.S. Cole, H.H. Woodbury and J.F. Schetzina, J. Appl. Phys., 55, 3166 (1984)

8. H.M. Manasevit and W.I. Simpson, J. Electrochem. Soc., 118, 644 (1971)

9. J.J. Dubowski, D.F. Williams, P.B. Swell and P. Norman, Appl. Phys. Lett., 46, 1081 (1985)

10. J.T. Cheung, M. Khoshnevisan and T. Magee, Appl. Phys. Lett., 43, 462 (1983)

11. R.N. Bicknell, N.C. Giles and J.F. Schetzina, Appl. Phys. Lett., 49, 1095 (1986)

12. R. Korenstein and B. Macleod, J. Crystal Growth, 86, 382 (1988)

13. P.L. Anderson, J. Vac. Sci. Technol., A4, 2162 (1986)

14. K. Yasuda, M. Ekawa, N. Matsui, S. Sone, Y. Sugiure, A. Tanaka and M. Saji, J.J. Appl. Phys., 29, 479 (1990)

15. P.I. Kuznetsov, L.A. Zhuravlev, I.N. Odin, V.V. Shemet and A.V. Novoselova, Inorg. Mater., 18, 779 (1982)

16. J.B. Mullin, S.J. Irvine and J. Tunnicliffe, J. Crystal Growth, 68, 214 (1984)

17. K. Zanio, "Semiconductors and Semimetals", Academic, New York (1980)

18. N.C. Giles-Tayer, R.N. Bicknell, D.K. Blanks, T.H. Myers and J.F. Schetzina, J. Vac. Sci. Technol. A3, 76 (1985) 

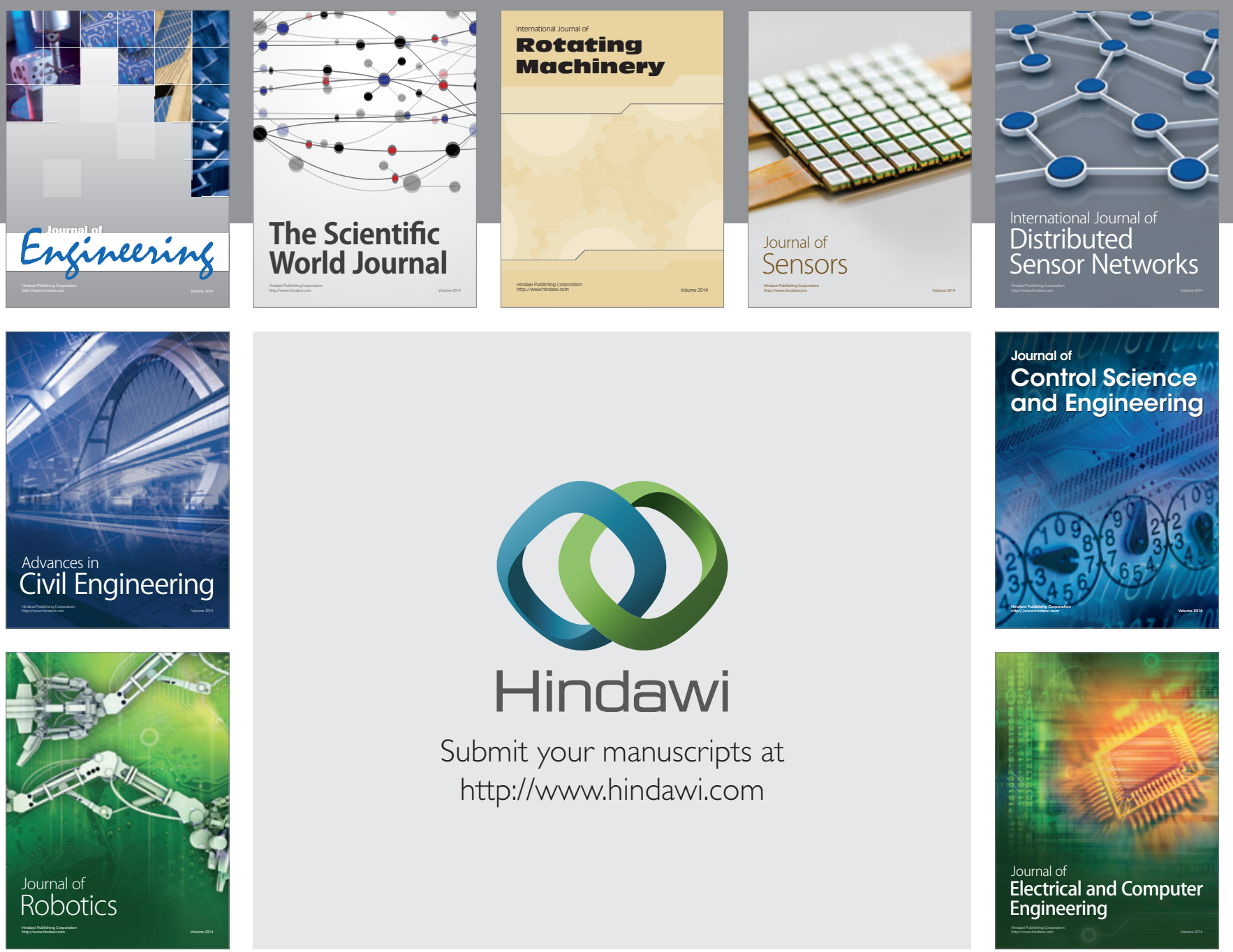

Submit your manuscripts at

http://www.hindawi.com
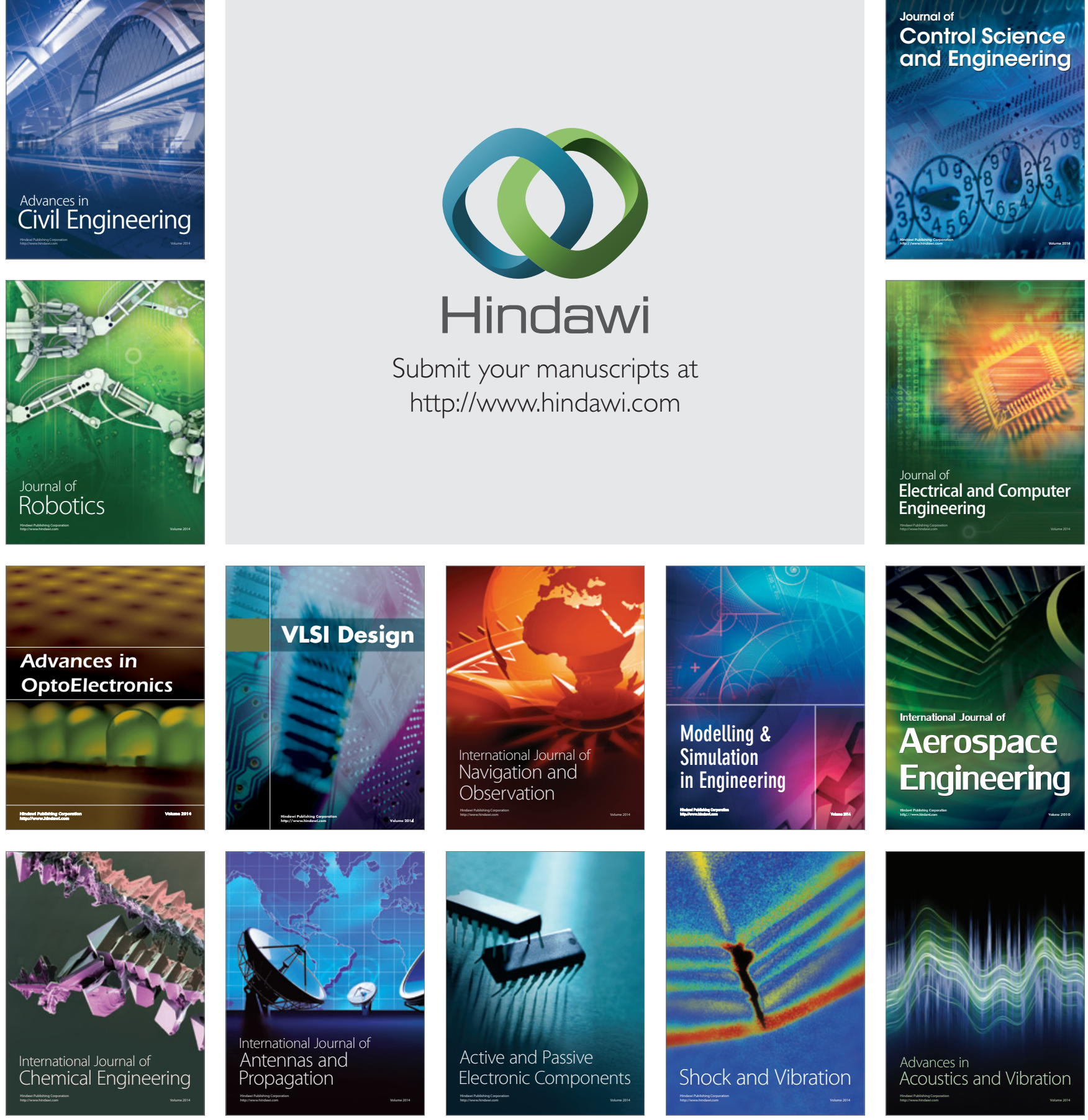